SAMUEL ARAÚJO

\title{
Movimentos
}

musicais:

Guerra-Peixe

\section{para ouvir,}

dançar

\section{e pensar}

SAMUEL ARAÚJO

é coordenador do

Laboratório de

Etnomusicologia da

Universidade Federal

do Rio de Janeiro. 


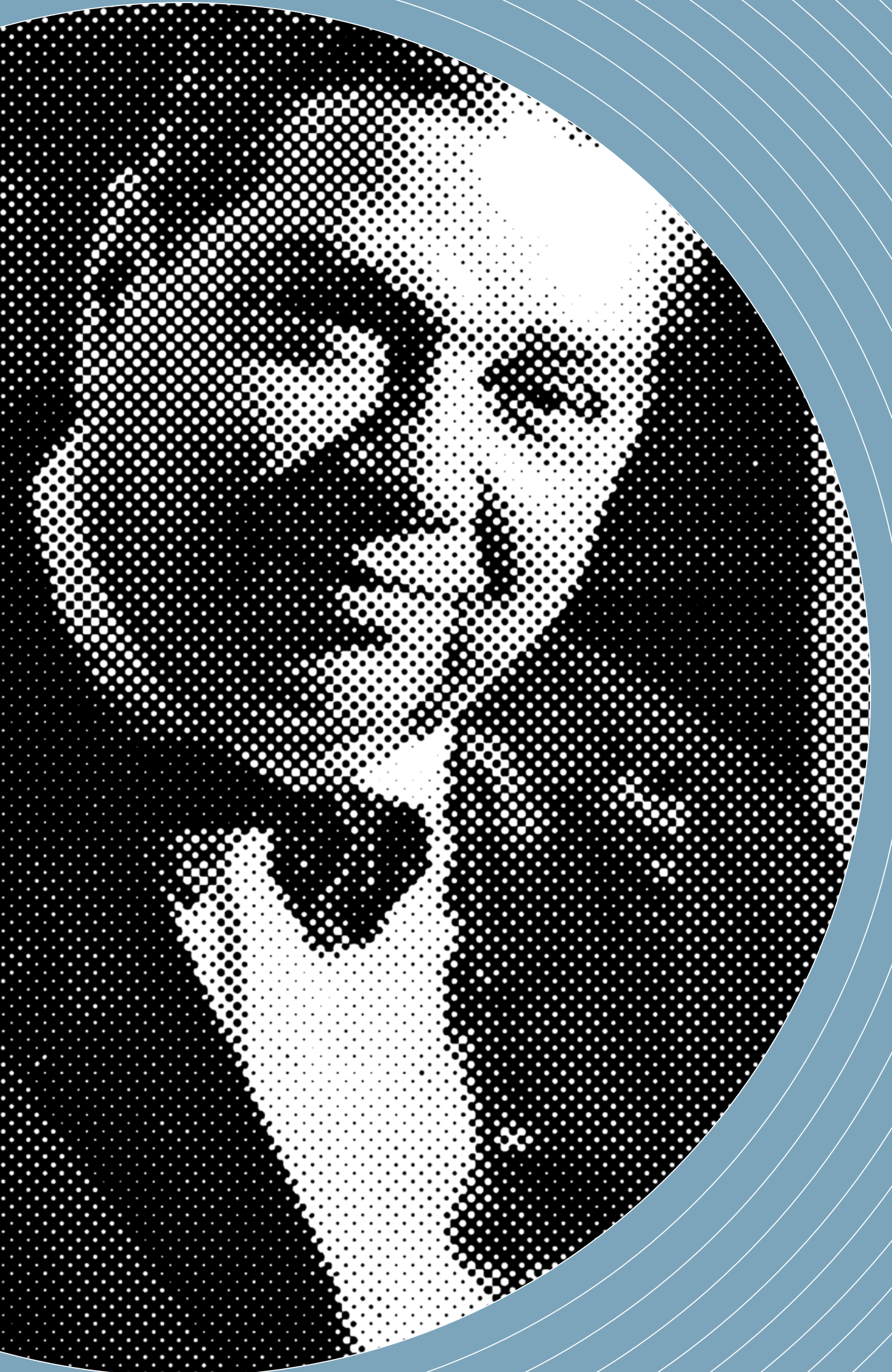




\section{RESUMO}

Entre os tópicos da produção escrita,jornalística ou acadêmica, sobre a música no Brasil encontra-se a configuração eventual de movimentos, explicitamente reconhecidos ou não por seus protagonistas,em que criação musical étomada como vetor, único ou conjugado, de mudanças significativas de cunho estético, técnico, comportamental e/ou político, capazes de afetar contundente ou tangencialmente os rumos gerais da sociedade brasileira.Assim,tomando uma série de indagações como ponto de partida, a proposta deste artigo é examinar um repertório musical produzido por demanda de mercado e, possivelmente por isso, não avaliado como "movimento" no sentido aqui enunciado:a música composta por Guerra-Peixe para orquestra de dança de salão ao final dos anos 1930 e início dos anos 40.

Palavras-chave: movimentos musicais, música brasileira, Guerra-Peixe.

\section{ABSTRACT}

Among what has been written about music in Brazil, either by journalists or by academics, there is the occasional portrayal of movements, explicitly acknowledged or not by their protagonists, in which musical creation is taken as either a single orjoint vector of significant aesthetic, technical, behavioral and/orpolitical changes, able to affect either sharply or tangentially the general paths taken by Brazilian society at large. By taking a series of questions as a departure point, this article aims at analyzing a musical repertoire produced by market demands and, possibly because of that, not regarded as a "movement" in the sense herein enunciated: the music composed by Guerra-Peixe for dance hall orchestra by the end of the 1930s and early 1940 s.

Keywords: musical movements, Brazilian music, Guerra-Peixe. 


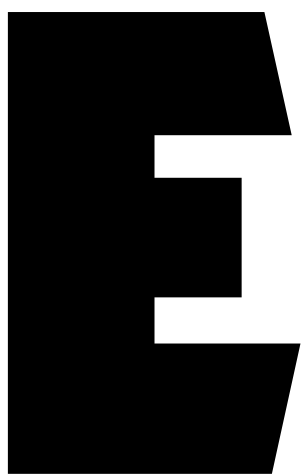

ntre os tópicos da produção escrita, jornalística ou acadêmica, sobre a música no Brasil encontra-se a configuração eventual de movimentos, explicitamente reconhecidos ou não por seus protagonistas, em que a criação musical é tomada como vetor, único ou conjugado, de mudanças significativas de cunho estético, técnico, comportamental e/ou político, capazes de afetar contundente ou tangencialmente os rumos gerais da sociedade brasileira. No campo da música de concerto, seriam exemplos possíveis o nacionalismo modernista, abrangendo figuras como Mário de Andrade, Villa-Lobos ou Camargo Guarnieri, ou a digestão antropofágica tupiniquim do expressionismo musical germânico, ou o música viva, enquanto na assim chamada música popular, de variado apelo comercial, a bossa nova, a tropicália, o Clube da Esquina, e o b-rock são índices de movimentos, alguns dos quais identificados a posteriori, a que correspondem manifestos verbalizados por ao menos parte de seus agentes representativos-de caráter, portanto, mais convencional -, como no caso do nacionalismo (cf. Andrade, 1928), do música viva (cf. Kater, 2001;Egg, 2004) ou da tropicália, manifestos essencialmente fonográficos, como os casos da bossa nova (o disco Chega de Saudade de Elizeth Cardoso, 1958) e do Clube da Esquina (álbum duplo homônimo), ou manifestos comportamentais em eventos públicos midiáticos, como a consagração do b-rock no primeiro festival Rock In Rio, em 1985. 


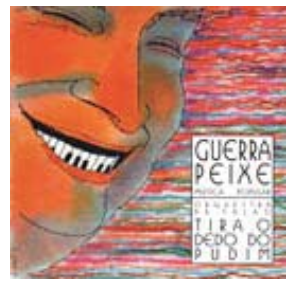

Tira o Dedo

do Pudim,

Guerra-Peixe:

Música Popular, independente,

2000
Emprega-se aqui o termo "longa duração" na perspectiva de processos ou movimentos históricos que, ultrapassando os marcos de ciclos, interciclos ou crises temporalmente mais circunscritos, abrem possibilidades mais ricas de interpretação dos processos comuns que lhes dão sentido (cf. Braudel, 1992).
Se é característica comum a esses movimentos, como se disse acima, os respectivos ideais de mudança neles embutidos terem apoio em processos musicais, afetando significativamente padrões perceptivos, intelectuais e comportamentais da sociedade de modo mais abrangente, seriam eles eventos pontuais de sentido e importância sócio-histórica circunscrita ou careceriam do reconhecimento de sua intermitente continuidade em processos históricos de longa duração ${ }^{1}$ ? Nesse sentido, seria possível e producente falar de movimentos cujos protagonistas não se propunham a tal fim e cujos efeitos não tenham sido até hoje reconhecidos na literatura? Que contribuição movimentos sociomusicais trariam à compreensão das relações entre o local e o global no Brasil, e que perspectivas originais, se alguma, abririam ao debate sobre projetos político-sociais para o país? Que relações travam os movimentos musicais com interesses mercadológicos e ligados à música como meio de sobrevivência?

Tomando as indagações acima como ponto de partida, a proposta deste artigo é examinar um repertório musical produzido por demanda de mercadoe, possivelmente por isso, não avaliado como "movimento" no sentido aqui enunciado: a música composta por Guerra-Peixe para orquestra de dança de salão no Brasil ao final dos anos 1930 e início dos anos 40, em meio, portanto, à Segunda Guerra Mundial. Propõe-se tomá-lo como parte originalmente significativa de um movimento mais extenso, retrospectiva e prospectivamente, sendo crucial ao debate interno sobre as definições e projetos de nação, interpelando temática comum, a saber, as relações estéticas, técnicas e políticas entre o local e o global. Para tal examinaremos aspectos selecionados da citada produção de Guerra-Peixe para orquestra de salão, de cunho estético, técnico-musical e político, envolvidos numa produção que se poderia pensar, sob a ótica logocêntrica dominante no meio acadêmico (cf. Bornheim, 2001), como resultante de interesse estritamente funcional e comercial, portanto não merecendo interesse intelectual, e talvez daí advindo seu amplo silenciamento na literatura especializada.

Desvelando processos que vêm a público originalmente em sua música para o salão de baile metropolitano, e somente mais tarde, de modo verbalizado, em sua produção de cunho musicológico, procurarse-á evidenciar, por um lado, a simultânea articulação entre o pulsar dos salões e os embates estéticos e técnicos que nortearam a reflexão sobre a música e a cultura de modo geral em círculos intelectuais pequeno-burgueses do Brasil e do mundo, e, por outro, a deglutição antropofágica de índices da globalização modernizante no período em questão.

\section{NOTA BREVE SOBRE 0 LEGADO DE GUERRA-PEIXE}

Compositor, orquestrador e intérprete de sons e ideias, César Guerra-Peixe (191493) legou às gerações que lhe sucedem um imenso e valioso patrimônio de saber, ainda pouco conhecido não somente entre o público em geral, mas também entre os militantes do campo da música em suas diversas facetas.

Lançamentos fonográficos, bibliográficos e virtuais, aliados à execução intermitente, porém, incessante de sua obra musical e à proliferação de teses acadêmicas, preenchem pouco a pouco lacunas de conhecimento em relação a sua produção como compositor (Neves, 1981; Silva, 1993; Faria Jr., 1997; Nonno, 1997; Malamut, 1999; Kater, 2001; Rosa, 2001; Lima, 2002; Vetromilla, 2002; Gusmão, 2004; Vianna, 2005; Miguel, 2006; Martins, 2007; Cavalcanti, 2008; Milani, 2008; Egg, 2004; Gado, 2005; Duarte, 2005; Assis, 2006; Corradi Jr., 2006), orquestrador (Leme, 2000; Fecher, 2005; Pereira, 2006; Gianesella, 2009; Lacerda, 2009), intérprete (Aguiar, 1995; Souza, 1998; Faria, 2003) e pesquisador (Guerra-Peixe, 2007). Aqueles que acessam esse manancial crescente podem, inegavelmente, fazer uma ideia bem mais clara hoje de sua importância no 
cenário da criação musical, mas há ainda notável carência de trabalhos de prospecçãoe divulgação mais sistemáticos e abrangentes, restando ainda a descoberto reflexões mais densas sobre facetas como, por exemplo, sua produção para cinema, sua ação como pedagogo ou sua ativa e prolongada presença no campo da música popular como compositor e orquestrador ${ }^{2}$.

\section{ESFERA PÚBLICA, ORQUESTRAS DE SALÃO E MERCADO MUSICAL}

A música para o salão de baile do século XVIII, em relação de contiguidade com as de danças rurais e bailes domésticos entre as classes sociais presentes no meio urbano, tem relação direta com o nascimento da assim chamada esfera pública ${ }^{3}$,em que anônimos ou nem tanto passam a poder usufruir das oportunidades de sociabilidade regidas por formas mercantilizadas pré-industriais de entretenimento. Para Paul Nettl, pioneiro no estudo das relações entre música e dança no Ocidente, a consolidação da contradança na Inglaterra no período acima aludido como dança com participação igualitária de vários casais, em oposição às danças de salão do barroco, que privilegiavam a participação individual de determinados casais hierarquicamente superiores, seria significativo fator a sustentar "na nova ordem, a igualdade de direitos e liberdade dos sexos" (Nettl, 1929, p. 587). Guerra-Peixe, em texto de $1971^{4}$, em que apresenta uma articulada exposição de seu trajeto estilístico com exemplos musicais retirados de sua obra escrita até então, também faz menção à contradança como elo entre o salão de dança burguês e a sala de concerto, citando como exemplo, sua estilização por ninguém menos que Ludwig van Beethoven:

“16. [...] Quem examine as Contradanças de Beethoven verifica que as mesmas não se distanciam muito da música de salão de sua época salvo pelo talento e habilidade técnica do compositor. $\mathrm{E}$ tais danças são todas de origem popular com a devidaestilização para os salões" (Guerra-Peixe, 1971, p. 16).

Bruno Kiefer (1983), discorrendo sobre a chegada das danças populares urbanas europeias ao Brasil e sua influência na música de concerto, fornece referências que sugerem o início do século XIX, e mais precisamente a chegada da corte portuguesa ao Rio de Janeiro, como seu marco provável.

Um ambiente espaçoso o bastante para eventuais mesas e cadeiras, serviços de bebida e comida, além, obviamente, de um espaço para dança e acomodações para número variável de músicos, o salão de baile oferece ao habitante das áreas metropolitanas uma modalidade atrativa de diversão $v i s$-à-vis o trabalho alienado que começa a se tornar regra de sobrevivência para a maioria. Enquanto tem como requisito indispensável ${ }^{5}$ a ação de músicos executantes "ao vivo", grosso modo, do século XVIII a meados do século XX, a música composta para essa finalidade encontrará, a partir da década de 1920 , no rádio e no disco, pouco mais tarde no cinema, seus principais meios de difusão massiva, tendo como subproduto a edição de partituras para o próprio mercado de orquestras de salão.

No Brasil, o registro desse repertório de época é encontrado hoje em acervos fonográficos de colecionadores particulares ou em partituras impressas por editoras comerciais, encontráveis em bibliotecas públicas e privadas, e provavelmente feitas para fins de registro de direito autoral ou mesmo comercialização restrita. As obras de Guerra-Peixe que tomaremos aqui como eixo de nossa análise foram impressas na primeira metade dos anos 1940 , constando de conjuntos de partes cavadas (partituras separadas para cada instrumento de um dado conjunto), contendo uma espécie de sugestão nada rígida para a execução de cada instrumento (piano, contrabaixo, saxofones, trombones ou trompetes), que podem ser notas musicais com relativo detalhamento de suas respectivas durações e relações de
2 Importantes passos iniciais nessa direção são a coletânea Guerra-Peixe: Músico Brasileiro (Faria Jr. et alii 2007) e o sítio virtual www. guerrapeixe.com

3 ○ termo "esfera pública" é aqui utilizado no sentido proposto por Jurgen Habermas (1989) "[...] como a esfera das pessoas privadas reunindo-se enquanto público; logo, elas reivindicaram que a esfera pública fosse regulada desde instância superior contra as próprias autoridades públicas, de modo a confrontá-las em debate sobre as regras gerais governando as relações na esfera basicamente privatizada, mas publicamente relevante, da troca de mercadorias e trabalho social"' (tradução do autor da tradução inglesa).

4 Texto intitulado "Principais Traços Evolutivos da Produção Musical" e anexado ao manuscrito Catálogo de Obras, com as obras escritas até aquele ano. Ambos podem ser acessados em: www.guerrapeixe.com.

5 As proliferação e a sofisticação de tecnologias de reprodução sonora tornaram obviamente mais dispendioso e, de certo ponto de vista, dispensáve o emprego de músicos para execução "ao vivo". 
simultaneidade. No caso da amostra aqui comentada, originada do arquivo pessoal do compositor e hoje depositada na $\mathrm{Se}$ ção de Música da Biblioteca Nacional, ajunta-se ainda uma partitura com notação manuscrita em cifra alfanumérica para violão, e eventualmente outra, para bateria, também manuscrita, com registro do compasso (esquema regulador das proporções temporais abstraídas de obras musicais) acompanhado de indicações por escrito de gêneros conhecidos (por exemplo, "tempo de samba" ou “marcha”), especificando mais precisamente eventuais passagenschave em notação rítmica.

Esses vestígios de uma prática hoje excepcional, mas que certamente se constituiu em mercado viável para músicos em épocas passadas, pouco parecem dizer aos músicos de hoje, e consequentemente a suas possíveis plateias, já que, em grande medida, esse material não é mais veiculado sobre qualquer suporte. Uma análise mais detalhada de suas características revela, no entanto, aspectos ainda pouco estudados de movimentos musicais de mais longa duração, uma espécie de elo perdido entre os mesmos, interpelando temáticas que estão presentes em momentos antecedentes e subsequentes da produção musical no Brasil, como a relação entre os processos históricos brasileiro e de outras partes do mundo, as relações entre a hegemonia do logocentrismo no Ocidente e a subordinação do sensível ao escrutínio da razão (Bornheim, 2001), e a consequente presunção de contradição ou incompatibilidade entre a corporalidade, mais notadamente a de conteúdo sensual, e processos de intelecção fina.

A contribuição de Guerra-Peixe a esse movimento musical é bastante interessante nesse sentido, pois se inicia com a produção citada acima de repertório musical para o salão de baile, composta, publicada, tocadae gravada ao início da década de 1940. Como veremos a seguir, boa parte das concepções técnico-musicais e estéticas contidas nesse repertório será, na década seguinte, revisitada por outros músicos e debatida reflexivamente em artigos do próprio Guerra-Peixe surgidos na imprensa diária, textos esses que funcionam quase como minimanifestos em torno dos dilemas da música e da arte em geral no Brasil.

\section{GUERRA-PEIXE E O TEMPO DA PANCADA}

Pesquisando acerca de outro tema na Seção de Música na Biblioteca Nacional, em 1997, encontrei um conjunto de obras de Guerra-Peixe, de quem havia sido ex-aluno de harmonia, contraponto e composição, com a designação "para orquestra de salão”. Reunida uma dessas obras, partituras de música exclusivamente instrumental trazendo impressa a atribuição de gênero "choro", pensei em convocar um grupo de amigos músicos para uma leitura informal daquele material. Como a instrumentação invariavelmente compreendia, além de piano, contrabaixo, violão e bateria, um quarteto de saxofones e eventualmente um ou dois trompetes e trombones, algumas excepcionalmente acrescidas de uma parte para violino, exigindo um efetivo difícil de conseguir para um ensaio experimental, limitamos esse encontro a um quarteto com piano, contrabaixo, violãoe um único saxofone alto, o mesmo músico o alternando com uma clarineta, quando, em determinadas peças, a melodia principal era destinada a saxofone soprano.

Uma primeira leitura nos revelou linguagem harmônica que registrava, nesse repertório de início dos anos 40, acordes já habituais no jazz norte-americano do período, e tornados idiomáticos na bossa nova cerca de quinze anos mais tarde, logo se espraiando por outros âmbitos da música brasileira. Kiefer (1983, pp. 60-1) sugere ter sido na segunda década do século XX o marco inicial da presença no Brasil da música para dança de procedência estadunidense. Segundo o autor, one-step e fox-trot, entre outros gêneros, já eram ouvidos em nossos salões de baile nessa época, executados por jazz-bands. Em sua origem, esses jazz-bands se subdividiam basicamente em 
dois formatos, o de um grupo relativamente reduzido, próprio do estilo improvisado conhecido como dixieland e associado a Nova Orleans (adotado, por exemplo, pelos Oito Batutas, de Pixinguinha e Donga), ou de orquestras mais amplas, executando arranjos preconcebidos e com a adição de instrumentos não convencionais dos primórdios do jazz como violino ou celesta, das quais são exemplos as de Paul Whiteman e de Simon Bountman, respectivamente nos Estados Unidos e no Brasil.

Outro aspecto a chamar atenção nos choros de Guerra-Peixe foi o trabalho meticuloso sobre a dimensão temporal da melodia principal, na qual características mais constantes do gênero não se encontravam ausentes, mas sempre deslocadas em relação ao seu esperado surgimento, algo simultaneamente instigante e desafiador, do ponto de vista de quem baila, exigindo não apenas o rotineiro, mas uma nova resposta de corpo e mente.

A análise posterior da primeira parte de uma melodia em particular, "Sátira", de 1943, mostrou ainda uma evidente pré-construção cerebral a partir da assim chamada escala cromática, que compreende os doze sons possíveis de uma escala no sistema de afinação musical ("temperado") tornado hegemônico no Ocidente a partir do século XVIII. Cada um desses sons aparece nesse exemplo sem repetição até que todos os outros também surjam, e sua duração respectiva, fundamental aos passos da dança, também segue processos típicos de elaboração da arte contrapontística na música de concerto europeia, a saber, a diminuição proporcional das durações das notas musicais entre trechos diferentes da mesma melodia, uma estratégia usada para garantir unidade formal à composição, “camuflando" a repetição na diferença.

Se esses eram exercícios cerebrais postos à prova no salão de baile em meio à sensualidade e diversão regidas pelo prazer corporal, expondo e interferindo nos embates entre estéticas e práticas musicais conflitantes no âmbito do país, tornaram-se abertos ao debate intelectual pelo próprio Guerra-Peixe em diferentes estágios de sua produção escrita. Nesse particular, passagens bastante elucidativas para o que consideramos o caminho de ruptura com a tirania logocêntrica, presente no repertório aqui aludido, constam da autoanálise do autor no já mencionado "Principais Traços Evolutivos da Produção Musical”. Embora seus comentários tenham como objeto suas composições para sala de concerto, revelam em diversos momentos a aproximação desta com o universo dos bailes urbanos, já expressa na abertura do texto:

“Até o término [1944] do curso de composição feito com Newton Pádua, as obras desta fase inicial assinalavam vaga feição nacional apenas na melodia. Ao todo, cerca de 20 obras que o autor exclui do seu catálogo. Permanece a Suíte Infantil n. 1, de 1942, que é imediatamente editada e se torna conhecidíssima das classes de iniciantes no Brasil inteiro. Aliás, a obra continha inicialmente um sexto movimento denominado 'Fanfarra', inspirado nos toques dos clarins que, nas festas carnavalescas, anunciavam os bailes do Teatro João Caetano. Ao solicitar a obra para a edição Kosmos, que dirigia para os Irmãos Vitale, Lourenço [sic] Fernandez sugeriu ao autor, sem apresentar razões, que fosse abolido o mencionado movimento" (Guerra-Peixe, 1971, p. 1).

Essa última observação deixa aberta uma questão importante para o nacionalismo musical modernista: os limites de aceitação das formas de expressão populares urbanas, vistas com extrema cautela por Mário de Andrade, em função de sua eventual “contaminação" por fórmulas comerciais (Wisnik, 1982). No entanto, como aponta Bruno Kiefer (1983, p. 14), durante as três primeiras décadas do século XX, a obra de compositores como Villa-Lobos, Francisco Mignone, Camargo Guarnieri e do próprio Lorenzo Fernandez já apresentavam vários exemplos de estilização de danças populares urbanas como a polca e a mazurca, e principalmente a valsa, já levada a um grande requinte em termos de elaboração composicional por autores europeus como os Johann Strauss, pai e filho, e Franz Lehar. 
No item seguinte de sua autoanálise estilística, Guerra-Peixe comenta seu encontro com o músico e pedagogo alemão Hans Joachim Koelreutter, que lhe iniciaria nos princípios da técnica dodecafônica a partir de 1944:

“Ao frequentar, em 1944, o curso particular de H. J. Koellreutter - a única pessoa que chegou ao Brasil para nos transmitir informações sobre a música contemporânea da época -, adota meses depois a técnica dos doze sons, e a partir deste momento sua obra se torna pronunciadamente instável quanto ao ritmo, um ritmo excessivamente complexo. Por essa época o autor não tem a menor preocupação nacionalizante. O seu pensamento estético pode ser resumido no seguinte: um motivo, um acorde ou um ritmo jamais deverá ser feito exata ou aproximadamente duas vezes; pois toda a repetição, tal e qual ou semelhante, não passaria de mero primarismo. Do exagerado conceito resultam problemas insuperáveis, em especial no que tange ao ritmo, pois torna-se evidente a impressão de falta de unidade formal" (Guerra-Peixe, 1971, p. 1).

Essa discussão oferece um interessante contraponto com a análise feita acima do choro "Sátira" para orquestra de salão (1943), em que encontramos, como assinalado anteriormente, a preocupação meticulosa em "camuflar" a repetição das sequências de durações respectivas de cada nota musical (ritmo), segundo o autor, necessária para garantir a unidade formal numa forma de expressão que se configura e evanesce em tempo real comoa música, assim como a predeterminação de não utilizar na melodia principal repetição de qualquer nota da escala cromática antes da exposição de cada uma das demais notas

7 Como a data de publicação de "Sátira", 1943, antecede em um ano seu encontro com Koellreutter, não é de todo impossível que Guerra-Peixe,de disposição intelectual permanentemente inquieta, já tivesse então informações sobre a técnica dodecafônica. componentes da referida escala, princípio idêntico, portanto, ao da técnica dodecafônica ${ }^{7}$. Neste exemplo particular, o efeito soa até hoje surpreendente, bem demonstrando sua preocupação com a renovação de um gênero já exaustivamente explorado, de acordo com o próprio Guerra-Peixe, por Heitor Villa-Lobos, fruto da imersão deste como músico atuante nas práticas dos chorões cariocas das três primeiras décadas do século XX. Mais adiante, nos "Princípios...", equaciona a posição do choro de maneira, a nosso ver, excessivamente pessimista:

"Neste ano de 1949 sobrevém um novo período de crise na composição. Tenta uma pequena $P$ eça para piano (que se perdeu), segundo os conceitos menos pretensiosos da música erudita nacional e mais ao alcance da maioria. É quando surgem perguntas como as seguintes:

1. Como evitar ser atraído para a órbita de Villa-Lobos? Este músico viveu, ele próprio, o choro (estilo de música urbana e conjunto típico) e o conhecia como poucos.

2. Teria o choro suficiente força de expressão para resistir ao tempo e permanecer atuante por período tão duradouro quanto conviesse à música erudita nacional?

3. Caso se concretizasse a já prevista decadência do choro e seu rápido desaparecimento, as obras nele inspiradas não viriam aparecer envelhecidas às gerações que não viveram esse tipo de música popular urbana? Ora, sabe-se que, uns mais outros menos, os restantes compositores flutuavam na órbita de Villa-Lobos, rica de personalidade; e o nordestino de outros compositores se limitava a umas poucas fórmulas quanto, apenas, à melodia. Fórmulas que também já se vinham gastando - coisa que não mudou até hoje, 1971. Quanto ao ritmo, de uma pobreza incrível num país onde a variedade é incalculável" (Guerra-Peixe, 1971, pp. 9-10).

Ainda que nos furtemos a analisar contraexemplos mais recentes, indicando caminhos de renovação do choro após a sua redescoberta, como repertório e estilo de tocar, por sucessivas gerações a partir precisamente da década de 1970, bastaria voltarmos a "Sátira" para vislumbrarmos possibilidades de renovação ainda hoje instigantes. E o próprio Guerra-Peixe nos fornece uma pista adicional para compreendermos a já comentada sensação de 
simultânea familiaridade e estranhamento quanto aos aspectos temporais. Em artigo publicado em novembro de 1950 no Diário de Notícias, de Salvador ${ }^{8}$, ao considerar criticamente as relações entre efeitos de irresolução e estabilidade rítmicas presentes em gêneros musicais forjados no Brasil, como o samba e a marcha cariocas, presentes até hoje no senso comum entre muitos músicos, argumenta que:

"Trata-se de uma pancada [ou baque] intensamente acentuada, executada no bombo ou 'surdo' em algumas formas da música popular, especialmente na marcha carioca, no samba e em formas que se aproximam destas... Existe, de fato, uma acentuação muito sensível que caracteriza o acompanhamento do instrumento de percussão acima referido, nas citadas danças. Esta acentuação é tão marcante que muitas vezes o executante é levado a eliminar uma outra pancada que serve de contraste - esta sem acento - para dar o completo realce à primeira. Porém, esta acentuação sistemática e que muitas vezes nos parece exagerada, não nos autoriza a afirmar que em certas músicas brasileiras 'o tempo forte é no segundo tempo do compasso..." (GuerraPeixe, 2007).

Passando a uma exposição detalhada da distinção muitas vezes contraditória entre concepções de tempo historicamente construídas pelo logocentrismo europeu para representar em partitura ofait accompli da composição musical e, por outro lado, as necessidades expressivas de compositores, intérpretes e, quando é o caso, bailarinos, Guerra-Peixe desconstrói a percepção de senso comum, domesticada por pressupostos da música de concerto europeia, sobre a pancada da baqueta no "segundo tempo". É importante notar que, embora constante no samba e na marcha, tal característica não era típica do choro até 1940 , donde a sensação de estranhamento causada em “Sátira" provir em grande medida da utilização surpreendente das características daqueles dois gêneros em campo relativamente distinto de prática musical.

\section{COMENTÁRIO FINAL}

À primeira vista, os exemplos aqui apresentados poderiam parecer se referir tão somente à questão técnico-musical, passando ao largo de movimentos de consequências mais abrangentes para a vida social. No entanto, como procuramos assinalar, todos são aprofundamentos críticos de preocupações de um criador brasileiro inserido nos debates de seu tempo, a saber, as relações entre o país e o resto do mundo, as alianças e conflitos conformando a ideia de nação e os aparatos que lhe são correspondentes, a imbricação entre os processos estéticos, sociais e políticos à base dessas discussões.

Não havendo espaço para uma exposição mais abrangente, abarcando sua obra composicional para a sala de concerto, cinema, rádio, disco e $\mathrm{TV}$, ou sua extensa produção musicológica, escolhemos estrategicamente aquele que talvez seja o setor mais desprestigiado de toda essa produção, a música feita para o salão de baile, cuja funcionalidade se toma em muitas esferas como antítese da "boa música”, da musique à penser. GuerraPeixe mesmodeu mostras de não a considerar significativa, em que pese evidência, por ele próprio registrada e aqui destacada, de nela exprimir muitas de suas preocupações estilísticas e formais mais sérias. Ainda assim, como também demonstrado, nela reconhece uma das bases para encontrar saídas diante dos impasses que sobrevinham da hegemonia no Brasil dos cânones da música de concerto europeia ao longo da década de 1940, tema de pertinente atualidade até os dias de hoje. Uma prova inequívoca disso, em suas próprias palavras,

"Data de 1946 quando escreve a Sinfonia n. 1 para pequena orquestra, empregando série de doze sons mais acessível, agora não simétrica. E isso parece traduzir algum processo mormente no referente ao objetivo de 'nacionalizar' o dodecafonismo. Usa, embora timidamente ainda, figurações da rítmica popularesca, que é o que conhece da chamada 'música popular' de consumo, escrita para vendagem fonográfica e rendi-
8 Texto intitulado "Engano na Apreciação de um Ritmo Brasileiro", republicado em coletânea de artigos de Guerra-Peixe (2007) e também disponível em http://www.guerrapeixe. com/index2.html. 
mentos de direito de execução. Importa dizer que apesar disso a Sinfonia n. 1 é qualificada pela Divisão de Música da BBC de Londres, como 'Composição altamente expressiva'; Fórmulas que também já se vinham gastando - coisa que não mudou até hoje, 1971. Quanto ao ritmo, de uma pobreza incrível num país onde a variedade é incalculável" (Guerra-Peixe, 1971, p. 4 - grifos meus).

Os dilemas refletidos nesse percurso são, portanto, algo muito além de um mero retorcer de questões técnico-musicais, revelando-se rico ângulo de abordagem de processos não apenas inerentes à sociedade brasileira, mas também ao espectro mais amplo da sociedade contemporânea, com sua crítica mais ou menos explícita à tirania logocêntrica sobre os sentidos e à consequente hegemonia do capitalismo avançado sobre outras formas de vida. Em relação de intermitência, mas não descontínua, com outros debates da vida social em diversos tempos e lugares, um movimento mais harmonioso entre razão e sentidos, mente e corpo, sentimento e sobrevivência emerge desse objeto negligenciado, a música para ouvir, dançar e pensar de Guerra-Peixe.

\section{BIBLIOGRAFIA}

AGUIAR, Ernani Henrique Chaves. César Guerra-Peixe, Seu Instrumento e a Sonata N. 1 para Violino e Piano. Dissertação de mestrado em Música. Universidade Federal do Rio de Janeiro, 1995.

ANDRADE, Mário. Ensaio sobre Música Brasileira. São Paulo, Chiaratto, 1928.

ASSIS, Ana Cláudia. Os Doze Sons e a Cor Nacional: Conciliações Estéticas e Culturais na Produção Musical de César Guerra-Peixe (1944-1954). Tese de doutorado em História. Universidade Federal de Minas Gerais, 2006.

BORNHEIM, Gerd. Metafísica e Finitude. São Paulo, Perspectiva, 2001.

BRAUDEL, Fernand. Escritos sobre a História. 2ª ed. São Paulo, Perspectiva, 1992.

CAVALCANTI, Maria Carolina de Lima. Análise e Interpretação de Nove Peças do Repertório Carioca para Conjuntos de Flautas Transversas. Dissertação de mestrado em Música. Universidade Federal do Rio de Janeiro, 2008.

CORRADI JUNIOR, Claudio José. César Guerra-Peixe: Suas Obras para Violão. Dissertação de mestrado em Música. Universidade de São Paulo, 2006.

DUARTE, Francisco José Bossois Hohlenwerger de Sá Del-Rei. “Desculpe, Foi Engano": o Saxofone de Aurino Ferreira num Choro de Guerra-Peixe. Dissertação de mestrado. Universidade Federal do Estado do Rio de Janeiro, 2005.

EGG, André Acastro. O Debate no Campo do Nacionalismo Musical no Brasil (Anos 40 e 50). Dissertação de mestrado em História. Universidade Federal do Paraná, 2004.

FARIA, Priscila Araújo. A Escrita Idiomática do Concertino para Violino e Orquestra de Câmara, de César Guerra-Peixe.Dissertação de mestrado em Música. Universidade Federal do Rio de Janeiro, 2003.

FARIA Jr., Antônio Emanuel Guerreiro de. Guerra-Peixe, sua Evolução Estilística à Luz das Teses Andradeanas. Dissertação de mestrado em Música. Universidade Federal do Estado do Rio de Janeiro, 1997.

FARIA Jr., Antônio Emanuel Guerreiro de et al. Guerra-Peixe - Um Músico Brasileiro. Rio de Janeiro, Lumiar/Chediak, 2007.

FECHER, Carlos Eduardo. Suíte Sinfônica n. 1 - "Paulista", de Guerra-Peixe: um Estudo da Orquestração como Retrato do Folclore. Dissertação de mestrado em Música. Universidade Federal do Estado do Rio de Janeiro, 2005.

GADO, Adriano Braz. Estudo da Técnica de Doze Sons em Obras Selecionadas: Hans Joachim Koellreutter e César Guerra-Peixe. Dissertação de mestrado em Música. Universidade Estadual de Campinas, 2005. 
GIANESELLA, Eduardo Flores. Percussão Orquestral Brasileira: Problemas Editoriais e Interpretativos. Tese de doutorado em Música. Universidade de São Paulo, 2009.

GUERRA-PEIXE, César."Principais Traços Evolutivos da Produção Musical", in www.guerrapeixe.com/ texto01.html, 1971.

Estudos de Folclore e Música Popular Urbana. Org. Samuel Araújo. Belo Horizonte/Rio de Janeiro, Editora da UFMG/Petrobrás Cultural, 2007.

GUSMÃO, Pablo da Silva. O Tempo e a Dinâmica no Primeiro Movimento da Sonatina № 2 para Piano de César Guerra-Peixe: um Estudo Pré-Interpretativo. Dissertação de mestrado em Música. Universidade Federal do Rio Grande do Sul, 2004.

HABERMAS, Jurgen. The Structural Transformation of the Public Sphere. Trad. Thomas Burger e Frederick Lawrence. Cambridge, MA, The MIT Press, 1989.

KATER,Carlos.MúsicaVivaeH.J.Koellreutter;Movimentosem DireçãoàModernidade.São Paulo,Musa, 2001.

KIEFER,Bruno.Música e Dança Popular;Sua Influência na Música Erudita.Porto Alegre,Movimento, 1983.

NEVES, José Maria. Música Contemporânea Brasileira. São Paulo, Ricordi, 1981.

LACERDA, Bruno Renato. Arranjos de Guerra-Peixe para a Orquestra da Rádio Nacional do Rio de Janeiro. Dissertação de mestrado em Música. Universidade Estadual Paulista, 2009.

LEME, Beatriz Campello Paes. Guerra-Peixe e as 14 Canções do Guia Prático de Villa-Lobos: Reflexões Acerca da Prática da Transcrição. Dissertação de mestrado em Música. Universidade Federal do Estado do Rio de Janeiro, 2000.

LIMA, Cecília Nazaré. A Fase Dodecafônica de Guerra Peixe; à Luz das Impressões do Compositor. Dissertação de mestrado em Música. Universidade Estadual de Campinas, 2002.

MALAMUT, Stael Viegas. A Flauta na Música de Câmara de Guerra Peixe. Dissertação de mestrado em Música. Universidade Federal do Estado do Rio de Janeiro, 1999.

MARTINS, Willa Soanne. A Expressão da Identidade Musical Através do Canto nas Trovas Capixabas e Alagoanas, de César Guerra-Peixe. Dissertação de mestrado em Música. Universidade Federal do Rio de Janeiro, 2007.

MIGUEL, Randolf Miguel. A Estilização do Folclore na Composição Musical de Guerra-Peixe. Dissertação de mestrado em Música. Universidade Federal do Estado do Rio de Janeiro, 2006.

MILANI, Margareth Maria.Prelúdios Tropicais de Guerra-Peixe: uma Análise Estrutural e sua Projeção na Concepção Interpretativa da Obra. Dissertação de mestrado em Música. Universidade Federal da Bahia, 2008.

NETTL, Paul."Notes on the History of Dance", in The Musical Quarterly 15 (4), 1929, pp. 583-9.

NONNO, Joaquim Inácio de. Nacionalismo, Enculturação e Estética: uma Leitura dos Ciclos Drummondiana e Sumidouro de César Guerra-Peixe. Dissertação de mestrado em Música. Universidade Federal do Rio de Janeiro, 1997.

PEREIRA, Leandro Ribeiro. Rádio Nacional do Rio de Janeiro: a Música Popular Brasileira e Seus Arranjadores (Década de 1930 à Década de 1960). Dissertação de mestrado em Música. Universidade Federal do Rio de Janeiro, 2006.

ROSA, Robervaldo Linhares. Obras Dodecafônicas para Piano de Compositores do Grupo Música Viva: H.J. Kollreutter, Cláudio Santoro, C. Guerra-Peixe e Edino Krieger - Uma Proposta Interpretativa. Dissertação de mestrado em Música. Universidade Federal do Estado do Rio de Janeiro, 2001.

SILVA, Luiz Eduardo de C. Domingues. A Análise das Técnicas Composicionais na Sonata N. 2 de Guerra-Peixe. Dissertação de mestrado em Música. Universidade Federal do Rio de Janeiro, 1993.

SOUZA, Ângelo Alexandre Dell'Orto de. Aspectos Interpretativos da Sonata N. 2 para Violino e Piano de Guerra-Peixe. Dissertação de mestrado em Música. Universidade Federal do Rio de Janeiro, 1998.

VETROMILLA, Clayton Daunis. Obra para Violão de César Guerra-Peixe. Dissertação de mestrado em Música. Universidade Federal do Rio de Janeiro, 2002.

VIANA, Fábio Henrique. A "Comunicabilidade"nas Peças Dodecafônicas para Flauta e Piano de César Guerra-Peixe.Dissertação de mestrado em Música. Universidade Federal de Minas Gerais, 2005. WISNIK, José Miguel."Getúlio da Paixão Cearense - Villa Lobos e o Estado Novo,"in Enio Squeff e José Miguel Wisnik. O Nacional e o Popular na Cultura Brasileira/Música. São Paulo, Brasiliense, 1982. 